\title{
Clinical Significance of Preheparin Serum Lipoprotein Lipase Mass in Coronary Vasospasm
}

\author{
Takashi Hitsumoto, MD; Kunio Yoshinaga, MD; Hirofumi Noike, MD; \\ Masahito Kanai, MD; Kohji Shirai, MD*
}

\begin{abstract}
The present study investigated the clinical significance of preheparin serum lipoprotein lipase (LPL) mass in coronary vasospasm by examining its relationship with the acetylcholine-induced coronary artery response in patients without angiographically demonstrable atherosclerotic coronary artery disease (CAD). The subjects were 39 men who had suspected CAD and who underwent coronary angiography. Coronary vasospasm was defined as a marked luminal narrowing or total occlusion provoked by the intracoronary administration of acetylcholine. Preheparin LPL mass was lower $(\mathrm{p}<0.05)$ in 25 subjects in whom vasospasm was induced by the acetylcholine provocation test than in the 14 subjects with a negative response. As regards preheparin LPL mass, the subjects with multiple vessel spasm had significantly low concentrations $(\mathrm{p}<0.05)$ compared with single vessel spasm, although serum lipid levels were not significantly different. Multiple regression analysis revealed only preheparin LPL mass had a significant absolute t-value (2.016) among the coronary risk factors. Low preheparin LPL mass is interpreted as reflecting an impaired acetylcholine-induced coronary relaxation in coronary vasospasm and preheparin LPL mass may be useful as a marker of early stage coronary atherosclerosis that is not detectable by angiography. (Jpn Circ J 2001; 65: 539-544)
\end{abstract}

Key Words: Acetylcholine; Coronary angiography; Coronary vasospasm; Preheparin serum lipoprotein lipase mass

$\mathbf{L}$ ipoprotein lipase (LPL) catalyzes hydrolysis of triglyceride (TG) in circulating lipoproteins ${ }^{1}$ and exists in preheparin serum, even though lipase activity is scarcely detected. Because preheparin serum LPL mass may be involved in the progression of coronary atherosclerosis, the correlation between them needs to be examined.

Acetylcholine (Ach) has been used clinically in catheterization laboratories as a standard spasm provocation test. The ACh-induced vascular relaxation is mediated by nitric oxide (NO) released from the endothelium, and an impaired relaxation response reflects endothelial dysfunction3,4 Endothelial function plays an important role in the regulation of circulation and impaired endothelium-dependent dilatation has been reported in patients with risk factors for vascular disease such as old age, dyslipidemia, hypertension, diabetes mellitus, and smoking5-9 Previous studies have shown that endothelial dysfunction is an early event in atherosclerosis and precedes occlusive vascular disease in both experimental primate models and human heart transplant recipients $!^{10,11}$ Kugiyama et al reported that deficiency of endothelial NO activity plays an important role in the pathogenesis of coronary vasospasm, 12 and a recent clinical study using intravascular ultrasound demonstrated early signs of atherosclerosis at the site of focal and diffuse spasms caused by intracoronary administration of ACh!3,14

(Received December 11, 2000; revised manuscript received February 5, 2001; accepted February 19, 2001)

Cardiovascular Center and *Internal Medicine, Clinical Laboratory Medicine, Sakura Hospital, School of Medicine, Toho University, Chiba, Japan

Mailing address: Takashi Hitsumoto, MD, Department of Internal Medicine, Sakura Hospital, School of Medicine, Toho University, 564-1 Shimoshizu, Sakura-City, Chiba 285-0841, Japan. E-mail: ddda @ cc.rim.or.jp
Thus, impaired ACh-induced relaxation in coronary vasospasm reflects coronary endothelial dysfunction and early stage coronary atherosclerosis.

We examined the relationship between preheparin serum LPL mass and the ACh-induced coronary artery response in patients without angiographically significant coronary artery stenosis, and elucidated the clinical significance of preheparin LPL mass in regard to coronary endothelial dysfunction and early stage coronary atherosclerosis by comparing it with total cholesterol, TG, high density lipoprotein-cholesterol (HDL-C), low density lipoprotein-cholesterol (LDL-C) and other coronary risk factors.

\section{Methods}

Subjects

Thirty-nine men with suspected coronary artery disease (CAD) diagnosed from their symptoms as well as from non-invasive procedures (ECG abnormality, treadmill exercise test, thallium-201 myocardial scintigraphy) underwent coronary angiography after giving informed consent at the Cardiovascular Center of Sakura Hospital. The average age of the men was 56 years (standard deviation: \pm 25 ; range, 22-79 years). Blood samples were drawn upon fasting just before heparin injection preceding coronary angiography. The samples necessary for LPL mass measurement were frozen at $-80^{\circ} \mathrm{C}$ within $1 \mathrm{~h}$ of sampling.

\section{Angiographic Study}

Selective coronary angiography was performed using either the Judkins method with a transfemoral approach ${ }^{15}$ or the Sones method with a transbrachial approach ${ }^{16}$ in the morning after overnight fasting and without anti-angina medications, except in patients for whom it was judged dangerous to discontinue the therapy. Two experienced 
angiographers reviewed all coronary angiograms unaware of the patient's clinical data. None of the coronary arteries had a stenotic lesion and the presence of a subtle irregular-

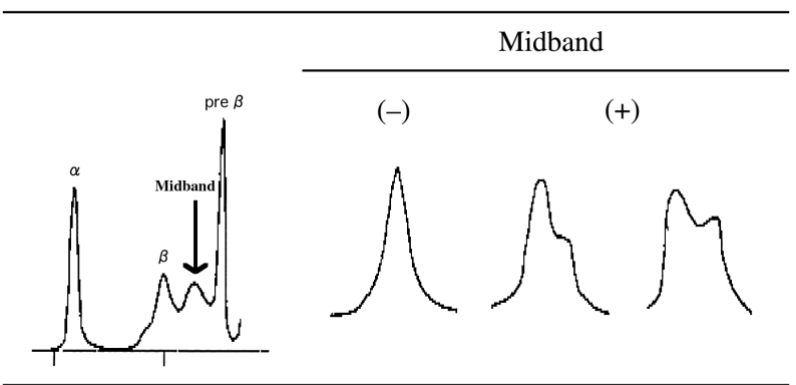

Fig 1. Evaluation of the midband. The eluted lipoprotein patterns were recorded by densitometer and when the individual peak was observed between the $\beta$ and pre $\beta$ lipoprotein bands or the shoulder was observed on the pre $\beta$ side of the $\beta$ lipoproteins, the midband was designated positive. ity of the arterial wall was classified as nearly normal. Coronary vasospasm was defined as a marked luminal narrowing or total occlusion provoked by intracoronary administration of $\mathrm{ACh}$ in at least one coronary vessel. Acetylcholine was dissolved in physiological saline, and incremental doses were injected $(20 \mu \mathrm{g}$ and $40 \mu \mathrm{g}$ into the right coronary, and $40 \mu \mathrm{g}$ and $80 \mu \mathrm{g}$ into the left coronary artery). The coronary vasospasm group was divided into 2: Group I = single vessel spasm, and Group II = multiple vessel spasms. The normal coronary group was defined as showing neither change nor extensive reaction to dilatation following intracoronary administration of ACh.

\section{Preheparin LPL Mass Assay}

LPL mass was measured by a sandwich enzyme-linked immunosorbent assay (ELISA) kit using a specific monoclonal antibody against lipoprotein lipase (Daiichi Pure Chemicals Co, Ltd, Tokyo, Japan), as described by Kobayashi et al17 The linearity of this assay system was observed from 5 to $400 \mathrm{ng} / \mathrm{ml}$. The within-run coefficient of variation was $2.8 \%$. Between-day coefficient of variation

Table 1 Baseline Clinical Characteristics

\begin{tabular}{lccc}
\hline \hline & $\begin{array}{c}\text { Normal coronary } \\
\text { group }(n=14)\end{array}$ & $\begin{array}{c}\text { Coronary vasospasm } \\
\text { group }(n=25)\end{array}$ & p value \\
\hline Age (years) & $54 \pm 16$ & $57 \pm 13$ & $N S$ \\
Coronary risk factor & & & $N S$ \\
Hypertension & $5(36 \%)$ & $13(52 \%)$ & $N S$ \\
Diabetes mellitus & $1(7 \%)$ & $2(8 \%)$ & $N S$ \\
Hyperuricemia & $1(7 \%)$ & $1(4 \%)$ & $N S$ \\
Obesity* & $5(36 \%)$ & $8(32 \%)$ & $N S$ \\
Smoking & $6(43 \%)$ & $15(60 \%)$ & $N S$ \\
Family history & $1(7 \%)$ & $2(8 \%)$ & $N$ \\
\hline
\end{tabular}

All values are mean $\pm S D$ followed by the range. *Body mass index $\geq 24$.
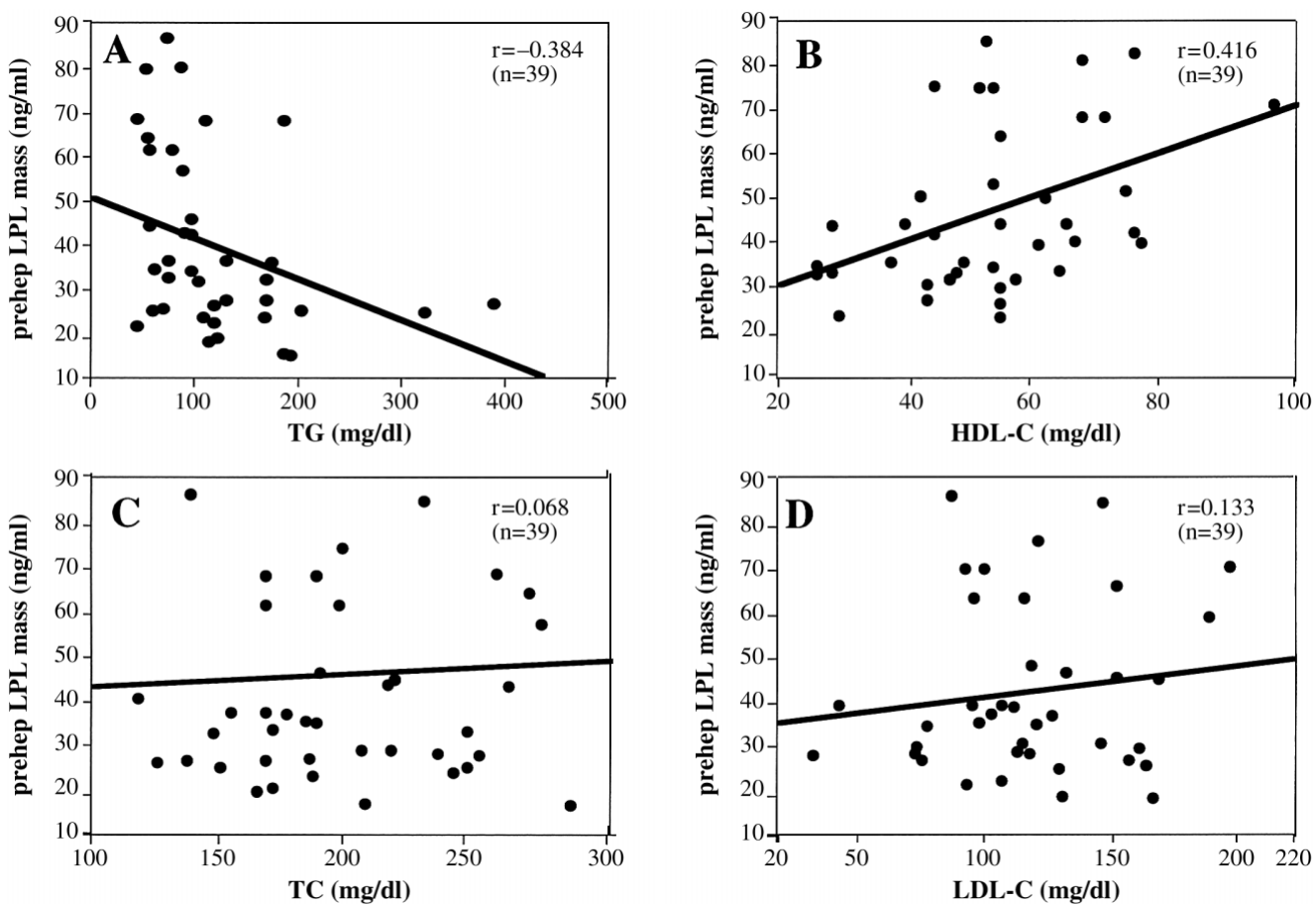

Fig 2. The correlation between preheparin LPL mass and serum lipids was studied in 39 men who underwent coronary angiography. A negative correlation between preheparin LPL mass and triglyceride $(r=-0.384, p<0.001)$ and a positive correlation between preheparin LPL mass and HDL-cholesterol $(r=0.416, p<0.001)$ were observed. 
Table 2 Serum Lipid Levels, Preheparin Lipoprotein Lipase (LPL) Mass and the Midband

\begin{tabular}{lccc}
\hline \hline & $\begin{array}{c}\text { Midband negative } \\
\text { group }(n=18)\end{array}$ & $\begin{array}{c}\text { Midband positive } \\
\text { group }(n=21)\end{array}$ & p value \\
\hline Age $($ years) & $52 \pm 14$ & $59 \pm 13$ & $N S$ \\
Total cholesterol $(\mathrm{mg} / \mathrm{dl})$ & $196 \pm 23$ & $179 \pm 33$ & $N S$ \\
Triglyceride $(\mathrm{mg} / \mathrm{dl})$ & $105 \pm 52$ & $186 \pm 122$ & $<0.05$ \\
HDL cholesterol $(\mathrm{mg} / \mathrm{dl})$ & $56 \pm 14$ & $44 \pm 1$ & $<0.01$ \\
LDL cholesterol $(\mathrm{mg} / \mathrm{dl})$ & $120 \pm 26$ & $98 \pm 35$ & $<0.05$ \\
Preheparin LPL mass $(\mathrm{ng} / \mathrm{ml})$ & $50 \pm 17$ & $40 \pm 15$ & $<.05$ \\
No. of coronary vasospasms/ & $10 / 8$ & $15 / 6$ & $N S$ \\
$\quad$ normal coronary & & & \\
\hline
\end{tabular}

All values are mean $\pm S D$ followed by the range. $H D L$, high density lipoprotein; $L D L$, low density lipoprotein.

Table 3 Serum Lipid Levels and Preheparin Lipoprotein Lipase (LPL) Mass

\begin{tabular}{lcc}
\hline \hline & $\begin{array}{c}\text { Normal coronary } \\
\text { group }(n=14)\end{array}$ & $\begin{array}{c}\text { Coronary vasospasm } \\
\text { group }(n=25)\end{array}$ \\
\hline Total cholesterol $(\mathrm{mg} / \mathrm{dl})$ & $192 \pm 23$ & $184 \pm 31$ \\
Triglyceride $(\mathrm{mg} / \mathrm{dl})$ & $138 \pm 67$ & $184 \pm 110$ \\
HDL cholesterol $(\mathrm{mg} / \mathrm{dl})$ & $48 \pm 13$ & $49 \pm 14$ \\
LDL cholesterol $(\mathrm{mg} / \mathrm{dl})$ & $116 \pm 26$ & $103 \pm 35$ \\
Preheparin LPL mass $(\mathrm{ng} / \mathrm{ml})$ & $51 \pm 16$ & $41 \pm 16$ \\
\hline
\end{tabular}

All values are mean $\pm S D$ followed by the range. ${ }^{*} p<0.05$. $H D L$, high density lipoprotein; $L D L$, low density lipoprotein.

was $4.3 \%$. Interference by serum TG from 50 to $1,500 \mathrm{mg} / \mathrm{dl}$ and serum HDL-C from 5 to $120 \mathrm{mg} / \mathrm{dl}$ was not observed.

\section{Lipid Analysis}

Total cholesterol and TG concentrations were measured enzymatically using a kit (Nippon Shoji Co, Ltd, Osaka, Japan) and an automatic analyzer (Hitachi 7150, Hitachi, Ltd, Tokyo, Japan). HDL-C was measured by the selective inhibition method (Daiichi Pure Chemicals) ${ }^{18}$ and LDL-C was calculated by the Friedwalds method (total cholesterolHDL-C-TG/5). The eluted lipoprotein patterns were recorded by densinometer. As shown in Fig 1 , when an independent peak was observed between the $\beta$ and pre $\beta$ lipoprotein bands or when a shoulder was observed on the pre $\beta$ side of the $\beta$ lipoprotein, the midband was interpreted as positive.

\section{Coronary Risk Factors}

Examined coronary risk factors were age, smoking, family history, hypertension, hyperuricemia, diabetes mellitus, total cholesterol, TG, HDL-C and body mass index. Smoking was positive with a current or past history of cigarette smoking. The family history was positive if angina pectoris and/or myocardial infarction were present in grandparents, parents and/or siblings. Diabetes mellitus was defined as present if fasting blood glucose was $>126$ $\mathrm{mg} / \mathrm{dl}$ and hemoglobin A $1 \mathrm{c}$ was $>6.5 \%$. Hyperuricemia was defined by a serum uric acid level of $>8.0 \mathrm{mg} / \mathrm{dl}$ and hypertension was defined as a history of systolic pressure $\geq 140$ $\mathrm{mmHg}$ or diastolic pressure $\geq 90 \mathrm{mmHg}$.

\section{Statistical Analysis}

The results were expressed as means \pm standard deviation. A t test and Mann-Whitney U test were used for group comparisons. P values less than 0.05 were considered significant. Multiple logistic regressions were performed with the SAS computer programs. Eleven explanatory risk factors including preheparin LPL mass were scored and subordinate variable was coronary vasospasm (normal coro- nary $=0$, coronary vasospasm $=1$ ). According to the analysis, an explanatory factor with a $t$ value of more than 2 was significantly correlated with the dependent variables.

\section{Results}

Baseline Clinical Characteristics (Table 1)

There were no significant differences in the coronary risk factors or medications.

Preheparin LPL Mass and Serum Lipid Levels in All Subjects Undergoing Coronary Angiography

A negative correlation between preheparin LPL mass and TG $(r=-0.384)$ and a positive correlation between preheparin LPL mass and HDL-C $(r=0.416)$ were observed (Fig 2A,B). There was not a significant correlation between preheparin LPL mass and either total cholesterol or LDL-C (Fig 2C,D).

\section{Comparison of the Serum Lipid Levels and Preheparin LPL Mass in the Midband Positive and Negative Groups (Table 2)}

The total cholesterol level did not differ between the 2 groups, but the TG levels were significantly higher in the midband positive group and the HDL-C $(\mathrm{p}<0.05)$ and LDL-C was significantly lower ( $\mathrm{p}<0.05$ for both) compared with the midband negative group. Preheparin LPL mass was significantly lower $(\mathrm{p}<0.05)$ in the midband positive group $(40 \pm 15$ vs $50 \pm 17 \mathrm{ng} / \mathrm{ml})$. There were more episodes of coronary vasospasm in the midband lipoprotein-positive group than in the midband lipoprotein-negative group, but not significantly.

\section{Comparison of the Serum Lipid Levels and Preheparin LPL Mass in the Normal and} the Coronary Vasospasm Groups (Table 3)

The total cholesterol, LDL-C and HDL-C levels did not differ between the 2 groups. The TG level was higher in the coronary vasospasm group, but not significantly. Preheparin 
Table 4 Comparison of Laboratory Findings Between Group I (Single-Vessel Spasm) and Group II (Multiple-Vessel Spasm)

\begin{tabular}{lcc}
\hline \hline & $\begin{array}{c}\text { Group I } \\
(n=11)\end{array}$ & $\begin{array}{c}\text { Group II } \\
(n=14)\end{array}$ \\
\hline Age (years) & $55 \pm 13$ & $57 \pm 12$ \\
Total cholesterol $(\mathrm{mg} / \mathrm{dl})$ & $197 \pm 23$ & $173 \pm 32$ \\
Triglyceride $(\mathrm{mg} / \mathrm{dl})$ & $106 \pm 33$ & $192 \pm 140$ \\
HDL cholesterol $(\mathrm{mg} / \mathrm{dl})$ & $55 \pm 13$ & $45 \pm 14$ \\
LDL cholesterol $(\mathrm{mg} / \mathrm{dl})$ & $121 \pm 30$ & $90 \pm 33$ \\
Preheparin LPL mass $(\mathrm{ng} / \mathrm{ml})$ & $48 \pm 17$ & $35 \pm 12$ \\
\hline
\end{tabular}

All values are mean $\pm S D$ followed by the range. ${ }^{*} p<0.05$. HDL, high density lipoprotein; $L D L$, low density lipoprotein; $L P L$, lipoprotein lipase.

Table 5 Multiple Regression Analysis of Coronary Vasospasm

\begin{tabular}{lcccc}
\hline \hline & $\begin{array}{c}\text { Partial regression } \\
\text { coefficient }(b)\end{array}$ & $\begin{array}{c}\text { Standard deviation } \\
\text { of } b(S E)\end{array}$ & $\begin{array}{c}\text { t value } \\
(b / S E)\end{array}$ & $\begin{array}{c}\text { Standard partial } \\
\text { regression coefficient }\end{array}$ \\
\hline$X$ & & & & \\
$\quad$ Preheparin LPL mass & -0.013 & 0.007 & -2.016 & -0.466 \\
HDL cholesterol & -0.012 & 0.008 & -1.382 & -0.326 \\
Smoking & 0.235 & 0.181 & 1.299 & 0.244 \\
Age & 0.008 & 0.008 & 0.951 & 0.231 \\
Total cholesterol & -0.002 & 0.004 & -0.689 & -0.161 \\
Hypertension & 0.112 & 0.199 & 0.563 & 0.117 \\
Diabetes mellitus & 0.076 & 0.344 & 0.222 & 0.042 \\
Family history & 0.045 & 0.270 & 0.168 & 0.032 \\
Triglyceride & 0.001 & 0.001 & 0.126 & 0.028 \\
Obesity (BMI) & -0.003 & 0.031 & -0.104 & -0.023 \\
Hyperuricemia & 0.019 & 0.448 & 0.043 & 0.009 \\
$Y \quad$ normal coronary=0 & coronary vasospasm=1 & & & \\
\hline
\end{tabular}

Constant $($ Intercept $)=0.57, F=0.88$. Multiple correlation coefficient $(R)=0.264$. LPL, lipoprotein lipase; HDL, high density lipoprotein; BMI, body mass index.

LPL mass was significantly lower $(\mathrm{p}<0.05)$ in the coronary vasospasm group compared with the normal coronary group $(41 \pm 16$ vs $51 \pm 16 \mathrm{ng} / \mathrm{ml})$.

\section{Serum Lipid Levels and Preheparin LPL Mass in the Coronary Vasospasm Group (Table 4)}

The coronary vasospasm group was divided into 2 groups (ie, Group I having single vessel spasm and Group II having multiple vessel spasms) and the total cholesterol and HDL$\mathrm{C}$ levels did not differ between them. The TG level was higher in the Group II, but not significantly. LDL-C was significantly lower $(\mathrm{p}<0.05)$ in Group II compared with Group I, as was preheparin LPL mass $(35 \pm 12$ vs $48 \pm 17$ $\mathrm{ng} / \mathrm{ml} ; \mathrm{p}<0.05)$.

\section{Multivariate Analysis of the Risk Factors for the Number of Lesions (Table 5)}

Among the 11 coronary risk factors, preheparin LPL mass had the highest absolute $t$ value (2.016) and was the only factor that significantly correlated with coronary vasospasm. The important risk factors of coronary vasospasm, such as smoking and serum lipid levels, were not significantly correlated.

\section{Discussion}

The present study observed a significantly low preheparin LPL mass in association with coronary vasospasm. Furthermore, the significantly low preheparin LPL mass was observed in the multiple vessel spasm group. Multivariate analysis revealed that among 11 coronary risk factors only preheparin LPL mass had a significant absolute $t$ value. These results suggest that a low preheparin LPL mass without observable lipase activity in vivo reflects the seriousness of the coronary vasospasm, although it is still unclear why, and that it is the most important of the coronary risk factors.

\section{Preheparin LPL Mass and LPL Activity}

LPL analysis is conducted using post-heparin plasma, because LPL is detached from the endothelial cells by heparin and released into the blood stream 19 Previous clinical study have shown that post-heparin plasma LPL activity is decreased in hypertriglyceridemic subjects and has a strongly positive relation to the HDL-C level?20,21 The present study revealed a negative correlation between preheparin LPL mass and TG and a positive correlation with HDL-C (Fig 2), which is consistent with reports by Tronvall et $\mathrm{al}^{22}$ and Watanabe et $\mathrm{al}^{23}$ and suggests that preheparin LPL mass reflects the level of functioning LPL activity in vivo, even though lipase activity is not detected.

\section{Lipid Metabolism}

An impaired endothelium-dependent vasodilatation response has been reported in hypercholesterolemia ${ }^{24,25}$ and hypertriglyceridemia, ${ }^{26}$ but in the present study, the serum cholesterol and TG levels of patients with coronary vasospasm were not significantly elevated (Table 2 ). Inoue et al reported that remnant-like particle cholesterol (RLP-C) was associated with coronary vasospasm, even though in ACh-positive patients the strongly atherogenic lipids and lipoproteins, such as total cholesterol, LDL-C and lipopro- 
tein(a), were not as high as in ACh-negative patients. ${ }^{27}$ Sakata et al reported that the levels of remnants of or residual TG-rich lipoproteins were more meaningful than TG levels in coronary heart diseases 28 and taken together these reports indicate that TG-rich lipoprotein is the most important factor in coronary vasospasm even though the serum lipids level is not so significantly different. Atherogenesis of TG-rich lipoproteins, such as the remnants, or intermediate density lipoproteins has recently highlighted29,30

Dysfunction of LPL in retention of TG-rich lipoproteins has been reported as a problem, 31 in addition to apolipoprotein $E^{32}$ and the receptors for remnants 33 Shimada et al revealed a relationship between low LPL production and the development of atherosclerosis in transgenic mice 34 and Tsutsumi et al also reported the correlation after administering an LPL enhancer NO-1886 35 However, the mechanism is still not fully clarified. Shimada et al suggested that LPL over-expression decreased serum triglyceride-rich lipoprotein, especially remnant lipoproteins ${ }^{34}$ but Beisiegel et al reported that LPL works as a ligand of the remnants in the uptake of remnants to the liver, in addition to hydrolysis of TG ${ }^{36}$ Based on these observations, preheparin LPL mass may be promoting the clearance of atherogenic TG-rich lipoproteins. This is till controversial because Huff et al reported that inactive LPL does not promote the uptake of TG-rich lipoproteins into the HepG2 liver cells 37 Thus, LPL works to decrease serum TG-rich lipoprotein, but the real role of human preheparin LPL mass in the uptake of TG-rich lipoprotein has not been clearly delineated.

Significantly elevated TG, lower HDL-C and lower preheparin LPL mass was observed in the midband lipoproteinpositive group (Table 2), which was consistent with the results of Totsuka et al ${ }^{38}$ On the other hand, in the present study there were a greater number of ACh-positive patients in the midband lipoprotein-positive group than in the midband lipoprotein-negative group, but not significantly. These results suggest that preheparin LPL mass may reflect coronary vasospasm with the retention of TG-rich lipoproteins, such as remnant and intermediate density lipoproteins, but it is difficult to explain coronary vasospasm only on the basis of TG-rich lipoprotein.

\section{Insulin Resistance and Preheparin LPL Mass}

Recent clinical studies have demonstrated a link between insulin resistance syndrome and coronary vasospasm,26,39 and Feingold et al proposed that, in the case of insulin resistance syndrome, small-sized dense LDL are present, ${ }^{40}$ the same type of LDL that is often associated with coronary heart disease and which Juha et $\mathrm{al}^{41}$ reported were associated with in vivo impaired endothelial function. Insulin is one of the most important factors for production of LPL in adipose tissues ${ }^{42,43}$ and LPL activity is reduced by obstruction of insulin function. Shirai et al reported that an insulin sensitizer, troglitazone, increased preheparin LPL mass level accompanied by a decrease in TG and an increase in HDL-C levels and an increase in the size of the LDLs44 They also reported that preheparin LPL mass reflected some of the LPL produced in the whole body and was related to insulin sensitivity. All these results suggest that low preheparin LPL mass may reflect coronary vasospasm associated with insulin resistant syndrome in the presence of small-sized LDL.

\section{Study Limitations}

Several limitations should be noted when interpreting the results of this study.

(1) All medications were stopped for at least $12 \mathrm{~h}$, but long-acting calcium channel blockers and isosorbide nitrate may have had residual effects during the spasm provocation test.

(2) We evaluated the midband visually.

(3) The study population was small and so further investigation with a larger population is required.

\section{Conclusions}

A significantly low preheparin LPL mass was observed in patients with positive coronary vasospasm. Furthermore, it reflected the seriousness of the vasospasm, which suggests that it may be an important risk factor. Preheparin LPL mass may be a useful marker of early stage coronary atherosclerosis that is not detectable by angiography.

\section{Acknowledgment}

We are greatly indebted to Drs Takashi Uchi, Masaki Yoshinuma, Takeshi Sakurai and Kaneyuki Aoyagi for their assistance in conducting CAG studies. This work was supported by Toho University's 60th anniversary memorial fund and also by Dai-ichi Pure Chemical Co, Ltd.

We also thank Professor Dr Hisao Tomioka and Dr Hidefumi Ohsawa for critical analysis of this manuscript.

\section{References}

1. Nilsson-Ehle PA, Garfinkel AS, Schotz MC: Lipolytic enzymes and plasma lipoprotein metabolism. Ann Rev Biochem 1980; 49: 667-693

2. Hitsumoto T, Ohsawa H, Uchi T, Noike H, Kanai M, Yoshinuma M, et al: Preheparin serum lipoprotein lipase mass is negatively related to coronary atherosclerosis. Atherosclerosis 2000; 153: $391-396$

3. Furchgott RF, Zawadzki JV: The obligatory role of endothelial cells in the relaxation of arterial smooth muscle by acetylcholine. Nature 1980; 288: $373-376$

4. Ludmer PL, Selwyn AP, Shook TL, Wayne RR, Mudge GH, Alexander W, et al: Paradoxical vasoconstriction induced by acetylcholine in atherosclerotic coronary arteries. N Engl J Med 1986; 315: 1046- 1051

5. Yasue H, Matsuyama K, Okumura K, Morikami Y, Ogawa H: Responses of angiographically normal human coronary arteries to intracoronary injection of acetylcholine by age and segment: Possible role of early coronary atherosclerosis. Circulation 1990; 81: 482-490

6. Nakaishi T, Tamura A, Watanabe T, Mikuriya Y, Nasu M: Relationship between plasma oxidized low-density lipoprotein and the coronary vasomotor response to acetylcholine in patients with coronary artery disease. Jpn Circ J 2000; 64: 856-860

7. Taddei S, Virdis A, Ghiadoni L, Salvetti G, Salvetti A: Endothelial dysfunction in hypertension. J Nephrol 2000; 13: 205-210

8. Ding Y, Vaziri ND, Coulson R, Kamannna VS, Roh DD: Effect of simulated hyperglycemia, insulin, and glucagon on endothelial nitric oxide synthase expression. Am J Physiol (Endocrinol Metab) 2000; 279: $11-17$

9. Hirai N, Kawano H, Hirashima O, Motoyama T, Moriyama Y, Sakamoto T, et al: Insulin resistance and endothelial dysfunction in smokers: Effects of vitamin C. Am J Physiol (Heart Circ Physiol) 2000; 279: $1172-1178$

10. Harrison DG, Armstrong ML, Freiman PC, Heistad DD: Restoration of endothelium-dependent relaxation by dietary treatment of atherosclerosis. J Clin Invest 1987; 80: 1808-1811

11. Fish RD, Nabel EG, Selwyn AP, Ludmer PL, Mudge GH, Kloshenbaum JM, et al: Responses of coronary arteries of cardiac transplant patients to acetylcholine. J Clin Invest 1988; 81: 21 -31

12. Kugiyama K, Yasue H, Okumura K, Ogawa H, Fujimoto K, Nakao $\mathrm{K}$, et al: Nitric oxide activity is deficient in spasm arteries of patients with coronary spastic angina. Circulation 1996; 94: 266-272

13. Kijima M: Intravascular ultrasound in patients with vasospastic angina pectoris (abstract). J Am Coll Cardiol 1992; 19(Suppl A): 286A

14. Koyama J, Yamagishi M, Tamai J, Kawano S, Daikoku S, Miyatake $\mathrm{K}$ : Comparison of vessel wall morphologic appearance at sites of focal and diffuse coronary vasospasm by intravascular ultrasound. Am Heart J 1995; 130: 440-445

15. Sones FM Jr, Shirey EK, Prondift WL, Westcott RN: Cine coronary 
arteriography (abstract). Circulation 1959; 20: 773

16. Judkins MP: Selective coronary arteriography: Percutaneous transfemoral technique. Radiology 1967; 89: 815-824

17. Kobayashi J, Hashimoto H, Fukamachi I, Tashiro J, Shirai K, Saito Y, et al: Lipoprotein lipase mass and activity in severe hypertriglyceridemia. Clin Chim Acta 1993; 216: 113-123

18. Shirai K, Nema T, Hiroh Y, Itoh Y, Miyashita Y, Watanabe H: Clinical efficacy of the direct assay method using polymers for serum high density lipoprotein cholesterol. J Clin Lab Anal 1997; 11: 82-86

19. Peterson J, Bihain BE, Bengston-Olivecrona G, Deckelbaum RJ, Carpentier YA, Olivecrona T: Fatty acid control of lipoprotein lipase: A link between energy metabolism and lipid transport. Proc Natl Acad Sci USA 1990; 87: 909-913

20. Breier C, Muhlberger V, Drexel H, Herold M, Lisch HJ, Krapp E, et al: Essential role of post-heparin lipoprotein lipase activity and of plasma testosterone in coronary artery disease. Lancet 1985; 1: 1242 1244

21. Johansson J, Nilsson-Ehle P, Carlson LA, Hamsten A: $\mathrm{n}$ of lipoprotein lipase activities with high density lipoprotein subclass levels in men with myocardial infarction at a young age. Atherosclerosis 1991; 86: $111-122$

22. Tronvall P, Bengtsson-Olivecrona G, Karpe F, Hamsten A, Olivecrona $\mathrm{T}$ : Lipoprotein lipases mass and activity in plasma and their increase after heparin are separate parameters with different relations to plasma lipoproteins. Arterioscler Thromb Vasc Biol 1995; 15: 1086-1093

23. Watanabe H, Miyashita Y, Murano T, Hiroh Y, Itoh Y, Shirai K: Prehaparin serum lipoprotein lipase masses level: The effect of age, gender, and types of hyperlipidemias. Atherosclerosis 1999; 145: 4560

24. Casino PR, Kilcoyne CM, Quyyumi AA, Hoeg MJ, Panza JA: Role of nitric oxide in endothelium dependent vasodilatation in hypercholesterolaemic patients. Circulation 1993; 88: 2541-2547

25. Casino PR, Kilcoyne CM, Cannon RO, Quyyumi AA, Panza JA: Impaired endothelium dependent vascular relaxation in patients with hypercholesterolaemia extends beyond the muscarinic receptor. Am J Cardiol 1995; 75: 40-44

26. Shimabukuro M, Shinzato T, Higa S, Chibana T, Yoshida H, Nagamine F, et al: Enhanced insulin response relates to acetylcholine-induced vasoconstriction in vasospastic angina. $\mathrm{J} \mathrm{Am} \mathrm{Coll}$ Cardiol 1995; 25: 356-361

27. Inoue T, Saniabadi A, Matsunaga R, Hosho K, Yaguchi I, Morooka $\mathrm{S}$ : Impaired endothelium-dependent acetylcholine-induced coronary artery relaxation in patients with high serum remnant lipoprotein particles. Atherosclerosis 1998; 139: 363-367

28. Sakata K, Miho N, Shirotani M, Yoshida H, Takada Y, Takada A: Remnant-like particle cholesterol is a major risk factor for myocardial infarction in vasospastic angina with nearly normal coronary artery. Atherosclerosis 1998; 136: 225-231

29. Zilversmit DB: Atherogenic nature of triglycerides, post-prandial lipidemia and triglyceride-rich remnant lipoprotein. Clin Chem 1995; 41: $153-158$

30. Krauss RM, Lindgren FT, Williams PT, Kelsby SF, Brensike J, Vranizan K, et al: Intermediate-density lipoproteins and progression of coronary artery disease in hypercholestrolemic men. Lancet 1987;
2: $62-66$

31. Fojo S, Dugi KA: Structure, function and role of lipoprotein lipase in lipoprotein metabolism. Curr Opin Lipidol 1994; 5: 117-125

32. Ishibashi S, Brown MS, Goldsten JL, Gerard RD, Hammer RE, Herz $\mathrm{J}$ : Hypercholesterolemia in low density lipoprotein receptor knockout mice and its reversal by adenovirus-mediated gene delivery. $J$ Clin Invest 1993; 92: 883-893

33. Ishibashi S, Perrey S, Chen Z, Osuga JI, Shimada M, Harada K, et al: Role of the low density lipoprotein (LDL) receptor pathway in the metabolism cylomicron remnants. J Biol Chem 1996; 271: 22422 22427

34. Shimada M, Ishibashi S, Inaba T, Yagyu H, Harada K, Ohsuga J, et al: Overexpression of lipoprotein lipase reduced atherosclerotic lesions in low density lipoprotein receptor deficient mice (abstract). Circulation 1995; 92(Suppl I): 359

35. Tsutsumi K, Inoue Y, Shimada A, Shima A, Iwasaki K, Kawamura M, et al: The novel compound NO-1886 increases lipoprotein lipase activity with resulting evaluation of high density lipoprotein cholesterol and long-term administration inhibits atherogenesis in the coronary arteries of rats with experimental atherosclerosis. J Clin Invest 1993; 92: 411-417

36. Beisiegel U, Weber W, Bengtsson-Olivecrona G: Lipoprotein lipase enhances the binding of chylomicrons to low density lipoprotein receptor-related protein. Proc Natl Acad Sci USA 1991; 88: 8342 8346

37. Huff MW, Miller DB, Wolfe BM, Connelly PW, Sawyez CG: Uptake of hypertriglyceridemic very low density lipoproteins and their remnants by HepG2 cells: The role of lipoprotein lipase, hepatic triglyceride lipase, and cell surface proteoglycans. J Lipid Res 1997; 38: $1318-1333$

38. Totsuka M, Miyashita Y, Ito Y, Watanabe H, Murano T, Shirai K: Enhancement of preheparin serum lipoprotein lipase mass by bezafibrate administration. Atherosclerosis 2000; 153: 175-179

39. Shinozaki K, Suzuki M, Ikebuchi M, Takaki H, Hara Y, Tsushima M, et al: Insulin resistance associated with compensatory hyperinsulinemia as an independent risk factor for vasospastic angina. Circulation 1995; 92: $1749-1757$

40. Feingold KR, Grunfeld C, Pang M, Doerrler W, Krause R: LDL subclass phenotypes and triglyceride metabolism in non-insulin dependent diabetes. Arterioscler Thromb Basc Biol 1992; 12: 14961502

41. Juha V, Sari M, Anneli S, Satu V, Sanni L, Per-Henrik G, et al: Endothelial dysfunction in men with small LDL particles. Circulation 2000; 102: 716-721

42. Ong JM, Kirchgessner TG, Schotz MC, Kern PA: Insulin increases the synthetic rate and messenger RNA level of lipoprotein lipase in isolated rat adinocyte. J Biol Chem 1998; 263: 12933-12938

43. Semenkovich CF, Wims M, Noe L, Chan L: Insulin regulation of lipoprotein lipase activity in 3T3-L1 adipocytes is mediated at post transcriptional and post-translational levels. J Biol Chem 1989; 264: 9030-9038

44. Shirai K, Itoh Y, Sasaki H, Totsuka M, Murano T, Watanabe H, et al: The effect of insulin sensitizer, troglitazone, on lipoprotein lipase mass in preheparin serum. Diabetes Res Clin Pract 1999; 46: 35-41 